\title{
Myo-Inositol and Its Derivatives: Their Emerging Role in the Treatment of Human Diseases
}

\author{
Dhani Raj Chhetri* \\ Department of Botany, School of Life Sciences, Sikkim University, Gangtok, India
}

Myo-inositol has been established as an important growth-promoting factor of mammalian cells and animals. The role of myo-inositol as a lipotropic factor has been proven, in addition to its involvement as co-factors of enzymes and as messenger molecules in signal transduction. Myo-inositol deficiency leads to intestinal lipodystrophy in animals and "inositol-less death" in some fungi. Of late, diverse uses of myo-inositol and its derivatives have been discovered in medicinal research. These compounds are used in the treatment of a variety of ailments from diabetes to cancer, and continued research in this direction promises a new future in therapeutics. In different diseases, inositols implement different strategies for therapeutic actions such as tissue specific increase or decrease in inositol products, production of inositol phosphoglycans (IPGs), conversion of myo-inositol (MI) to D-chiro-inositol (DCl), modulation of signal transduction, regulation of reactive oxygen

\section{OPEN ACCESS}

Edited by:
Letizia Polito,

Antonio Simone Laganà,

University of Insubria, Italy

Revaz Solomonia,

Ilia State University, Georgia

*Correspondence:

Dhani Raj Chhetri

drchhetri@cus.ac.in

Specialty section:

This article was submitted to Experimental Pharmacology and Drug Discovery,

a section of the journal Frontiers in Pharmacology

Received: 19 June 2019 Accepted: 12 September 2019 Published: 11 October 2019

Citation:

Chhetri DR (2019) Myo-Inositol and Its Derivatives: Their Emerging Role in the Treatment of Human Diseases. Front. Pharmacol. 10:1172. doi: 10.3389/fphar.2019.01172 species (ROS) production, etc. Though inositol pharmacology is a relatively lesser-known field, recent years of research has generated a critical mass of information on the subject. This review aims to summarize our current understanding on the role of inositol derivatives in ameliorating the symptoms of different diseases.

Keywords: myo-inositol, phospholipid, cyclitol, phytic acid, lipodystrophy, D-chiro-inositol

\section{INTRODUCTION}

Inositols are polyols having six-carbon ring structure where each carbon is hydroxylated. A number of these sugar-alcohol isomers are biologically active, of which myo-inositol (MI) is the most common (Majumdar et al., 1997). It constitutes a component of membrane phospholipids and mediates osmoregulation (Majumder and Biswas, 2006). Its phosphorylated derivatives act as second messengers in signal transduction pathways (Berridge, 2009), mediate phosphorylation of proteins (Saiardi et al., 2004), participate in chromatin remodeling and gene expression (Odom et al., 2000; Shen et al., 2003), and facilitate mRNA export from the nucleus (York et al., 1999).

Altered MI levels have been observed in the brains of patients of Alzheimer's disease, those suffering from mental disorders, and suicide and stroke victims (McLaurin et al., 1998; Macri et al., 2006). High fetal inositol concentrations in the cerebrospinal fluid have been attributed to the pathogenesis of Down's syndrome (Acevedo et al., 1997). Administration of MI has been found to be therapeutic for obsessive-compulsive disorder and panic disorder (Seelan et al., 2009). Lower frontal cortex MI is linked to the pathophysiology of depression and concomitant sleep symptoms (Urrila et al., 2017).

MI deficiency causes high accumulation of triacylglycerol, cholesterol, and non-esterified lipids in the mammalian liver. A minimum threshold level of free MI deters the formation of fatty liver 
(Burton and Wells, 1974; Hayashi et al., 1974a; Hayashi et al., 1974b). Hence, the metabolic understanding of MI status in any biological organ or system is primarily dependent on MIPS activity and its regulation.

\section{Chemistry}

Chemically inositols are isomers of hexahydroxy-cyclohexanes. Among the nine possible geometrical isomers of inositol, seven are optically inactive or "meso," and the remaining two form a chiral pair. The planar structures of the different isomers of this compound are presented in Figure 1. The molecule of MI has one axial and five equatorial hydroxyl groups. The axial hydroxyl group at position 2 is most stable to hydrolysis.

L-myo-inositol-1-phosphate synthase (MIPS) catalyzes the first step in the biosynthesis of all myo-inositol-containing compounds (Seelan et al., 2009). It converts glucose-6-phosphate to myo-inositol-1-phosphate (MIP). The phosphate moiety in MIP is subsequently removed by myo-inositol-1-phosphatase (IMPase) to produce free MI (Majumder and Biswas, 2006).

In addition, this compound could also be produced by cyclic synthesis (Agranoff et al., 1958; Paulus and Kennedy, 1960) and the hydrolysis of phosphatidylinositol. Although MIP is the intermediate common to both pathways, two different forms of compound are produced, the L-form by the synthetic pathway and the D-form by the cyclic pathway (Parthasarathy and Eisenberg, 1986). However, both the isomers are catalyzed by IMPase (Eisesnberg, 1967), which produces MI.

\section{Myo-Inositol in Disease and Medicine}

Elevated MI levels have been observed in Alzheimer's disease, gliomatosis cerebri, diabetes mellitus, systemic lupus erythematosus, multiple sclerosis, etc. Further, decreased brain levels of MI were observed in chronic hepatic and hypoxic
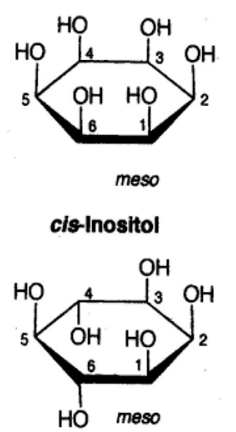

myo-Inositol

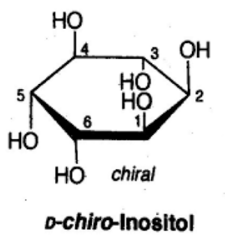

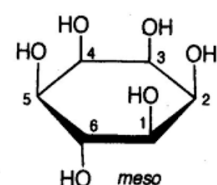
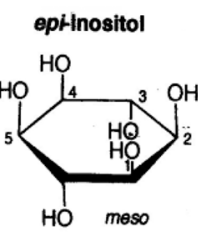

muco-Inositol

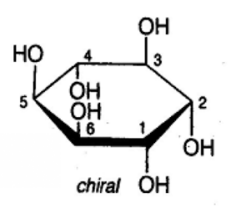

L-chiro-Inositol
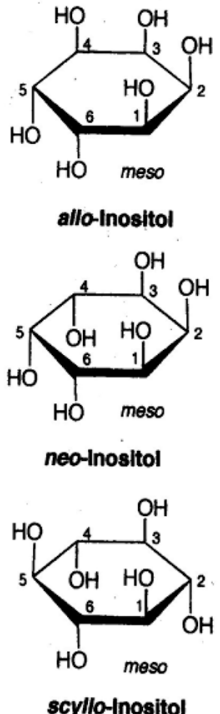

FIGURE 1 | The planar structure of nine possible stereoisomers of inositol. encephalopathy, stroke, acute thyrotoxic Graves' disease, toxoplasmosis, cryptococcosis, and lymphoma (Haris et al., 2011). In the following section, important diseases that are influenced by $\mathrm{MI}$ and its derivatives (Table $\mathbf{1}$ ) have been reviewed.

\section{Dyslipidemia and Cardiac Diseases}

Ever since it was known that MI deprivation in diet resulted in fatty liver condition in rats (Burton and Wells, 1974, Hayashi et al., 1974a; Hayashi et al., 1974b), the interest regarding its therapeutic value developed. MI also reduced the accumulation of hepatic triglyceride in the liver (McCrea and Camilli, 2009). Treatment with MI assisted in the removal of cholesterol from the myocardium, resulting in the decrease in lipid buildup in the heart that improved heart function. The reduction in myocardial lipid content ultimately resulted in the decrease in left ventricular stiffness (Regan et al., 1973).

A family of proteins called myotubularins which are actually inositol-3-phosphatases that dephosphorylate $\mathrm{PI}_{3} \mathrm{P}$ and $\mathrm{PI}(3,5) \mathrm{P}_{2}$ are implicated in cardiomyopathy. It has been found that mutations in the genes coding for the aforementioned proteins caused cardiomyopathy (McCrea and Camilli, 2009). Nebivolol, a beta-blocker drug, induces vasorelaxation through activation of inositol phosphate metabolism (Parenti et al., 2000). Calcification of heart vessels is an undesirable attribute of cardiovascular disease (CVD), and $\mathrm{IP}_{6}$ acts as a crystallization inhibitor of calcium salts in vitro, reducing the calcification of coronary arteries (Grases et al., 2000).

\section{Diabetic Complications}

It is a known fact that, in diabetic animals, there is limited metabolism of fructose in the nerve system leading to the accumulation of sorbitol and fructose, which is responsible for peripheral neuropathy (Grabby, 1973). This causes a decrease in the motor nerve conduction velocity as well as in the MI concentration of the sciatic nerve at the onset of diabetes (Greene et al., 1975). These anomalies could be prevented by the exogenous administration of MI (Palmano et al., 1977).

Endothelial dysfunction (ED) caused by hyperglycemia and hyperlipidemia is an early feature of diabetes (Nacimento et al., 2006). Inositol phosphoglycans (IPGs) are generated rapidly in response to insulin and have an insulin-like effect in vivo and in vitro (Huang et al., 1999). In human urine, the level of chiro-inositol is decreased, while the MI content increased in diabetic subjects. The decreased urinary chiro-inositol is inversely correlated to insulin resistance. Administration of D-chiro-inositol (DCI) in diabetic humans effectively decreased hyperglycemia and hypertriglyceridemia (Larner, 2002).

In type 2 diabetic subjects, the higher levels of MI and the lower levels of DCI are referred to as inositol imbalance. Chiroinositol deficiency and imbalance with myo-inositol are directly related to insulin resistance (Larner et al., 2010).

\section{Cancer}

Carcinogenesis in various organs may be inhibited by MI. Significant suppression of liver carcinogenesis by the oral 
administration of MI has been observed in mice (Nishino et al., 1999). Benzo[a]pyrene (B[a]P), a carcinogen derived from tobacco, causes lung tumor in rodents through its metabolite, anti-7,8-dihydroxy-9,10-epoxy-7,8,9,10-tetrahydrobenzo[a] pyrene $(\mathrm{B}[\mathrm{a}] \mathrm{PDE})$. Interestingly, the same metabolite inhibits the differentiation of small airway epithelial cells (SAE) in humans. MI protects SAE cells against such inhibitory effects (Jyonouchi et al., 1999). When MI was added to dexamethasone (another compound that prevents pulmonary neoplasia), an additive effect was observed on the inhibition of lung carcinogenesis (Wattenberg, 1999). Administration of MI decreases the multiplicity and size of surface tumors. It also decreases the size of adenocarcinoma, and therefore, it may be utilized for the chemoprevention of early pulmonary lesions (Kassie et al., 2010).

Striking anticancer effects of $\mathrm{IP}_{6}$ and inositol have been demonstrated in experimental models (Vucenic and Shamsuddin, 2003). In colon, breast, and metastatic lung cancer models, the effect of the combination of $\mathrm{IP}_{6}$ and $\mathrm{MI}$ was significantly better than by either of the two acting alone (Vucenic and Shamsuddin, 2003, 2006). IP 6 also inhibits prostate cancer $(\mathrm{Pca})$ cell proliferation and stimulates their apoptotic death. $\mathrm{IP}_{6}$ inhibits constitutive and growth factorinduced signaling pathways, which eventually leads to the inhibition of growth and the induction of apoptotic death of Pca cells (Gu et al., 2010).

\section{Mental Afflictions and Cognitive Diseases}

Evidences suggest that the MI level in brain is associated with changes in mood state. The MI levels in the frontal coretex of suicide victims and those suffering from bipolar disorder were 23 and 30\% lower, respectively, than the normal levels (Shimon et al., 1997). Patients of major depressive disorder have shown significantly lower $\mathrm{MI} /$ creatine ratios. The low levels of $\mathrm{MI}$ in the prefronatal/anterior cingulate cortex in major depressive disorder patients may be a consequence of altered glial metabolism (Coupland et al., 2005). Abnormal level of MI along with glutamate and glutamine was found in the brains of major depressive patients (Shirayama et al., 2017).

Administration of lithium causes a lowering of MI in the critical areas of the brain, and the effect is therapeutic. Lithium reduces $\mathrm{MI}$ level in the right frontal lobe in the brains of patients with manic depression. On the other hand, valproic acid (VPA) decreases the intercellular concentrations of inositol by inhibiting the key enzyme of MI biosynthesis, MIPS, in the human brain (Saltiel et al., 2004). Derivatives of VPA, valnoctamide (VCD), and valrocemide (VGD) are potent anticonvulsant drugs (Loscher and Nau, 1985; Anderson et al., 1992). The fact that $1 \mathrm{mM}$ VCD and VGD drastically inhibited human brain MIPS activity supports the view that these derivatives act as potential mood stabilizers (Saltiel et al., 2007).

The extra chromosome 21 in Down's syndrome (DS), which leads to dementia later in life, is phenotypically similar to Alzheimer's disease (AD). The presence of approximately $50 \%$ higher level of MI in DS patients suggests a gene dose effect of the extra chromosome 21, where the human osmoregulatory sodium/ myo-inositol cotransporter gene is located. Still, higher levels of
MI in older adults with DS are similar to that symptomatic of AD (Huang et al., 1999).

Synaptojanin-1 is a polyphosphosphoinositide phosphatase found in the neurons may have a role in the early onset of $\mathrm{AD}$ associated with DS. This enzyme is responsible for maximum of the $\mathrm{PIP}_{2}$ phosphatase activity in the brain and plays a critical role in synaptic transmission (Di Paolo and DeCamilli, 2006). The AD peptide $A \beta 42$ stimulates $\mathrm{PIP}_{2}$ cleavage and leads to abnormal $\mathrm{PIP}_{2}$ metabolism in $\mathrm{AD}$ (Berman et al., 2008). The genes encoding synaptojanin- 1 as well as the $A \beta 42$ precursor is located in chromosome 21, the triplication of which is responsible for DS (McCrea and Camilli, 2009). In DS patients, the level of synaptojanin-1 is increased, and the corresponding level of $\mathrm{PIP}_{2}$ is decreased.

People with mild cognitive disorder (MCI) have higher risk of conversion to $\mathrm{AD}$. In MCI, increased manifestation of MI occurs in the parietal white matter (WM), while in $\mathrm{AD}$, the elevation of MI was found throughout the WM (Zhu et al., 2006). Therefore, MI level in MCI may be regarded as an early indicator of $\mathrm{AD}$ (Siger et al., 2009).

Abnormalities in signal transduction play a role in the development of mood disorders. Activated PI-PLC cleaves $\mathrm{PIP}_{2}$ into $\mathrm{IP}_{3}$ and DAG, both of which are crucial molecules for signal transduction (Suh et al., 2008). Different PI-PLC enzymes are tissue-specific, and the different expression of some isoforms was described in pathological conditions (Lo Vasco et al., 2013). A role of PI-PLC $\beta 1$ in mood disorders has been suggested (Lo Vasco et al., 2012), and this hypothesis is in sync with the data obtained from schizophrenia models (Mc Omish et al., 2008). PI-PLC $\beta 1$ was also suggested to represent a molecular convergence point of several neurotransmitter pathways implicated in schizophrenia (Choi et al., 1989; Kim et al., 1997).

\section{Polycystic Ovary Syndrome}

Polycystic ovary syndrome (PCOS) is the most common form of the endocrine metabolic diseases affecting 6-10\% of women of reproductive age (Diamanti-Kandarakis et al., 1999). Insulin resistance (IR) and compensatory hyperinsulinemia play an integral role in the pathogenesis of this syndrome (Nestler, 1997). IR places these women at an increased risk of the development of cancer, hypertension, dyslipidemia, type 2 diabetes, and CVDs (Burghen et al., 1980). It is known that some functions of insulin require low molecular weight IPGs (Dona et al., 2012) and also that a deficiency in DCI containing IPGs and/or altered DCI metabolism may contribute to IR.

Besides IR, hyperandrogenism is another feature of PCOS. This hyperandrogenism is related to alteration of steroidogenesis in ovary and adrenal glands (Reyes-Munoz et al., 2018). Androgens act synergistically with follicle stimulating hormone (FSH) and modify steroidogenesis enzymes (Lenie and Smitz, 2009) which is also related to IR.

In women with PCOS, administration of DCI improves clinical features of the syndrome (Baillargeon et al., 2010). Moreover, combined therapy of MI and DCI improves the metabolic profile of obese PCOS patients, reducing the risk of CVD (Minozzi et al., 2013). MI may be incorporated into 
TABLE 1 | Pharmacological effects of myo-inositol and its derivatives against different disease symptoms.

\begin{tabular}{|c|c|c|c|}
\hline Effective inositol derivative & Affected tissue/organ & Disease/symptom & Reference \\
\hline $\mathrm{Ml}$ & Intestine (gerbil) & Lypodystrophy & Hegsted et al., 1973 \\
\hline $\mathrm{Ml}$ & Heart (rat) & Left ventricular stiffness & Regan et al., 1973 \\
\hline $\mathrm{Ml}$ & Liver (rat) & Fatty liver disease & $\begin{array}{l}\text { Burton and Wells, 1974; Hayashi et al., } \\
\text { 1974a; Hayashi et al., 1974b }\end{array}$ \\
\hline Ml & Brain (human) & Affective disorder & Barkai et al., 1978 \\
\hline $\mathrm{Ml}$ & Lung (mouse) & Tumor & Wattenberg, 1996 \\
\hline Ml & Brain (human) & Suicidal tendency & Shimon et al., 1997 \\
\hline $\mathrm{Ml}$ & Liver (mouse) & Cancer & Nishino et al., 1999 \\
\hline Ml & Lung (human) & Tumor & Jyonouchi et al., 1999 \\
\hline $\mathbb{I P}_{6}$ & Heart (rat) & Calcification of vessels & Grases et al., 2000 \\
\hline DCl-IPGs & Ovary (human) & PCOS & Sabuncu et al., 2001 \\
\hline $\mathrm{DCl}$ & Diabetic human & Endothelial dysfunction & Larner, 2002 \\
\hline $\mathrm{DCl}$ & Diabetic human & $\begin{array}{l}\text { Endothelial dysfunction, metabolic } \\
\text { syndrome, erectile dysfunction }\end{array}$ & Nacimento et al., 2006 \\
\hline $\mathrm{PIP}_{3}$ & $\begin{array}{l}\text { Nerve tissue, thyroid gland, colon, lung, } \\
\text { prostate gland, skin (human) }\end{array}$ & Cancer & $\begin{array}{l}\text { Luo et al., 2003; Osaki et al., 2004; Yuan } \\
\text { and Cantley, } 2008\end{array}$ \\
\hline $\mathrm{IP}_{6}+\mathrm{Ml}$ & Colon, breast, lung (human) & Cancer & $\begin{array}{l}\text { Vucenic and Shamsuddin, 2003; Vucenic } \\
\text { and Shamsuddin, } 2006\end{array}$ \\
\hline $\mathrm{Ml}$ & Brain (human) & Depression & $\begin{array}{l}\text { Coupland et al., 2005; Shirayama et al., } \\
2017\end{array}$ \\
\hline Ml & Fetal brain (human) & Down's syndrome & Seelan et al., 2009 \\
\hline $\mathrm{PIP}_{2}$ & Ovary, breast, lung, colon, stomach (human) & Cancer & $\begin{array}{l}\text { Engelman et al., 2006; Yuan and Cantley, } \\
2008\end{array}$ \\
\hline Ml & Brain (human) & Bipolar disorder & Saltiel et al., 2007 \\
\hline Ml & Brain (human) & Mild cognitive disorder & Berman et al., 2008; Voronov et al., 2008 \\
\hline Ml & Brian (human) & Alzheimer's disease & Siger et al., 2009 \\
\hline $\mathrm{DCl} / \mathrm{Ml}$ ratio & Diabetic human & Insulin resistance & Larner et al., 2010 \\
\hline Ml & Lung (mouse) & Tumor & Kassie et al., 2010 \\
\hline $\mathrm{IP}_{6}+\mathrm{Ml}$ & Breast (human) & Cancer & Bacic et al., 2010 \\
\hline $\mathrm{IP}_{6}$ & Prostate gland (human) & Cancer & Gu et al., 2010 \\
\hline $\mathrm{DCl}$ & Ovary (human) & Poor oocyte quality & $\begin{array}{l}\text { Carlomagno et al., 2011; Isabella and } \\
\text { Raffone, 2012; Simi et al., } 2017\end{array}$ \\
\hline $\mathrm{PIP}_{2}$ & Brain (human) & Schizophrenia & Lo Vasco et al., 2012 \\
\hline $\mathrm{Ml}+\mathrm{DCl}$ & Ovary (human) & PCOS & Minozzi et al., 2013 \\
\hline
\end{tabular}

DCI, D-chiro-inositol; ED, endothelial dysfunction; IP, ${ }_{6}$ Myo-inositol hexakisphosphate/phytic acid; IPG, inositol phosphoglycan; MI, Myo-inositol; PIP, phosphatidylinositol inositol 4,5-bisphosphate; PIP , phosphatidyl inositol 3,4,5-trisphosphate.

membrane phosphatidylinositols, or it may constitute IPGs in response to insulin. After its release, the IPGs interact with tissues involved in insulin action, thus potentiating the effects of insulin (Cheang et al., 2008). PCOS patients also exhibit an increased DCI/MI ratio (i.e., overproduction of DCI). This in turn leads to MI deficiency in the ovary. A balance between the two inositols is associated with IR and sensitivity (Heimark et al., 2013).

\section{Epilepsy}

In case of patients with temporal lobe epilepsy (TLE), MI level increases in the areas of seizure focus (temporal lobe) and its concentration decrease in the areas of seizure spread i.e., frontal lobe (Wellard et al., 2003). In the temporal lobe, the increased $\mathrm{MI}$ has been reported as a consequence of induction of $\mathrm{Na}+\mathrm{MI}$ cotransporter1 (SMIT1) after seizure activity in the area of seizure focus (Nonaka et al., 1999). The decreased MI in the frontal lobe reflects the osmolyte changes due to secondary effect of seizures. MI is transported from extracellular fluid into the cell through SMIT1. Overexpression of SMIT1 as well as MI supplementation increases intracellular phosphoinositide level and thereby alters phosphoinositide modulated ion channels suggesting the role of SMIT1 in signaling (Dai et al., 2016).

In experimental rats, MI treatment significantly reduces the severity of status epilepticus induced by kianic acid. The treatment reduced both the frequency and duration of spontaneous recurrent seizures, the main character of epilepsy. In addition, MI had significant effects on SMIT1 and leucine rich repeat-containing $8 \mathrm{~A}$, a component of volume regulated anionic channel (Tsverava et al., 2019).

The IMPA2 gene located at human chromosome $18 \mathrm{p} 11.2$ is responsible for febrile seizure (FS). IMPA2 codes for myo-inositol monophosphatase 2 that converts inositol monophosphate to MI and plays important role in phosphatidylinositol signaling pathway (Nakayama et al., 2004).

\section{DISCUSSION}

It is a foregone conclusion that MI and its derivatives exert various metabolic actions generating therapeutic outcomes. The activities are due to reduction in ROS generation, direct superoxide scavenging, protection of NO signaling, etc. For example, 
DCI may be considered a therapeutic agent against metabolic syndrome, endothelial dysfunction, and erectile dysfunction in diabetes patients (Nacimento et al., 2006), and MI may act as alternative of metformin, the most popular oral antidiabetic drug, because it interacts directly with insulin target tissues; however, it does not show the side effects of the drug (Dona et al., 2012). The insulin like action of MI and DCI is due to the production of inositol glycan secondary messengers. These inositol glycans may modulate cell signaling, and in addition, inositols are incorporated in cell membrane phospholipids (Lagana et al., 2018).

Depression and schizophrenia are severe psychiatric diseases that affect millions of individuals worldwide, consequently increasing global suicide levels (Ren, 2019). MI and its derivatives may be a very important adjunct therapy in such cases. The most important role of MI is found in the treatment of bipolar disorder. More often than not, lithium is the first line of defense in such cases. However, lithium treatment often leads to psoriasis and depression. In such cases, MI may act as a preferable alternative since it is effective in mood stabilization as well as in the treatment of psoriasis (Kontoangelos et al., 2010).

The importance of inositol in cancer lies in the fact that inositol3-phosphatase is a potent tumor suppressor, and its mutation leads to many types of cancers (Luo et al., 2003; Osaki et al., 2004; Yuan and Cantley, 2008). On the other hand, activating mutations in $\mathrm{PI}_{3}$-kinases have been reported in ovarian, breast, lung, colon, and gastric cancers (Engelman et al., 2006; Yuan and Cantley, 2008). In addition, in breast cancer patients, $\mathrm{IP}_{6}$ and $\mathrm{MI}$ may be a valuable adjunctive therapy. They also help in ameliorating the side effects and improving the quality of life (Bacic et al., 2010).

In oligoasthenospermia (OA), reduction in the number and motility of spermatozoa takes place. MI plays a crucial role in the osmoregulation of seminal fluid, thereby improving sperm motility. The antioxidant effect of MI also plays important role in the production and regulation of spermatozoa. Therefore, MI could be used in OA patients undergoing an in vitro fertilization cycle (Gulino et al., 2016). ROS affects not only the morphology and motility of spermatozoa but may also damage mitochondrial membrane potential (MMP) which in turn increases ROS production. MI may improve the sperm mitochondrial function, thereby improving sperm parameters in OA patients (Condorelli et al., 2017).

In women with PCOS, the combined therapy of MI plus DCI is able to influence the metabolism leading to improved lipid profile. However, in these patients, enhanced epimerization of MI to DCI takes place in the ovary, leading to excess DCI and less MI (Isabella and Raffone, 2012). This MI depletion eventually leads to poor oocyte quality (Carlomagno et al., 2011). MI

\section{REFERENCES}

Acevedo, L. D., Holloway, H. W., Rapoport, S. I., and Shetty, H. U. (1997). Application of stable isotope tracer combined with mass spectrometric detection for studying myo-inositol uptake by cultured neurons from fetal mouse: effect of trisomy 16. J. Mass Spectrom. 32, 395-400. doi: 10.1002/ (SICI) 1096-9888(199704)32:4<395::AID-JMS487>3.0.CO;2-\#

Agranoff, B. W., Bradley, R. M., and Brady, R. O. (1958). The enzymatic synthesis of inositol phosphatide. J. Biol. Chem. 233, 1077-1083. supplementation may salvage the situation by improving oocyte quality (Simi et al., 2017).

The spurt of research on inositol biochemistry started from the 1960s with different groups taking the lead on various aspects of the work (Ballou and Pizer, 1960; Shaktin and Tatum, 1961; Nagai and Funahashi, 1962, Plouvier, 1963; Michell and Hawthorne, 1965; Charalampous and Chen, 1966; Eisesnberg, 1967; Sherman et al., 1968; Dittmer and Douglas, 1969). Now, the molecules have again come into focus primarily due to the continued increase in lifestyle diseases and the long quest for effective and non-toxic cure for the same. ROS reduction may be one of the strategies of MI derivatives for its therapeutic functions. In diabetes and heart ailments, ROS generation by NADPH oxidase action and mitochondrial disruption could be inhibited by DCI (Vendrov et al., 2015). $\mathrm{IP}_{3}$ signaling may be another mechanism by which MI derivatives influence cellular functions. $\mathrm{IP}_{3}$ is responsible for $\mathrm{Ca}^{2+}$ release from the ER which raises the cytosolic $\mathrm{Ca}^{2+}$, and this in turn activates many enzymes and proteins. Indeed, defective $\mathrm{IP}_{3}$ receptors have been found responsible for many neurodegenerative disorders (Egorova and Bezprozvanny, 2018). Thus, MI and its derivatives may well play important roles not only to ameliorate cancers and psychotic diseases but also in many lifestyle diseases like obesity, diabetes, CVD, etc. This report tried to highlight these critical areas.

\section{AUTHOR CONTRIBUTIONS}

DC conceptualized the article, prepared the manuscript and did the editing.

\section{FUNDING}

Supported by National Mission on Himalayan Studies (NMHS) grant of the Government of India (Ref. No. NMHS/ MG-2016/005).

\section{ACKNOWLEDGMENT}

The author acknowledges the intellectual help provided by Prof. Shanti Swarup Sharma, Department of Botany, Sikkim University. The author is thankful to Ms. Tushita Karuna Chhetri for editing the language of the manuscript and Dr. Sachina Yonzone, Department of Botany, Darjeeling Government College is acknowledged for the assistance she has provided. The author is indebted to the referees for their constructive suggestions. Effect of valproate dose on formation of hepatotoxic metabolites. Epilepsia 33, 736-742. doi: 10.1111/j.1528-1157.1992.tb02355.x

Bacic, I., Druzijanic, N., Karlo, R., Skific, I., and Jagic, S. (2010). Efficacy of $\mathrm{IP}_{6}+$ inositol treatment of breast cancer patients receiving chemotherapy: prospective, randomized, pilot clinical study. J. Exp. Clic. Res. 29, 1-5. doi: 10.1186/1756-9966-29-12

Baillargeon, J.-P., Iuorno, M. J., Apridonidze, T., and Nestler, J. E. (2010). Uncoupling Betweeninsulinand release ofaD-Chiro-inositol-containinginositolphosphoglycan 
mediator of insulin action in obese women with polycystic ovary syndrome. Metab. Syndr. Relat. Disord. 8, 127-136. doi: 10.1089/met.2009.0052

Ballou, C. E., and Pizer, L. I. (1960). The absolute configuration of the myo-inositol 1-phosphate and a confirmation of the bornesitol configurations. J. Am. Chem. Soc. 82, 3333-3335. doi: 10.1021/ja01498a026

Barkai, A. I., Dunner, D L. Gross, H. A., Mayo. P., and Fieve, R. R. (1978). Reduced myo-inositol levels in cerebrospinal fluid from patients with affective disorder. Biol. Psychiatry 13, 65-72

Berman, D. E., Dall'Armi, C., Voronov, S. V., et al. (2008). Oligomeric amyloidbeta peptide disrupts phophatidylinositol-4,5 bisphosphate metabolism. Nat. Neurosci. 11, 547-554. doi: 10.1038/nn.2100

Berridge, M. J. (2009). Inositol trisphosphate and calcium signalling mechanisms. Biochim. Biophys. Acta 1793, 933-940. doi: 10.1016/j.bbamcr.2008.10.005

Burghen, G. A., Givens, J. R., and Kitabchi, A. E. (1980). Correlation of hyperandrogenism with hyperinsulinism in polycystic ovarian disease. J. Clin. Endocrinol. Metab. 50, 113-116. doi: 10.1210/jcem-50-1-113

Burton, L. E., and Wells, W. W. (1974). Studies on the developmental pattern of the enzymes converting glucose-6-phosphate to myo-inositol in the rat. Develop. Biol. 37, 35-42. doi: 10.1016/0012-1606(74)90167-5

Carlomagno, G., Unfer, V., and Roseff, S. (2011). The D-chiro-inositol paradox in the ovary. Fertil. Steril. 95, 2515-2516. doi: 10.1016/j. fertnstert.2011.05.027

Charalampous, F., and Chen, I. W. (1966). Inositol-1-phosphate synthase and inositol 1-phosphatase from yeast. Methods Enzymol. 9, 698-704. doi: 10.1016/0076-6879(66)09141-9

Cheang, K. I., Baillargeon, J. P., Essah, P. A., Ostlund, R. E. Jr, Apridonize, T., Islam, L., et al. (2008). Insulin-stimulated release of D-chiro-inositol containing inositolphosphoglycan mediator correlates with insulin sensitivity in women with polycystic ovary syndrome. Metabolism: Clin. Expt. 10, 1390-1397. doi: 10.1016/j.metabol.2008.05.008

Choi, W. C., Grefen, C. R., Suh, P. G., and Rhee, S. G. (1989). Immunohistochemical localization of a brain isozyme of phospholipase C (PLC III) in astroglia in rat brain. Brain Res. 499, 193-197. doi: 10.1016/0006-8993(89)91153-0

Condorelli, R. A., La-Vignera, S., Mongioi, L. M., Vitale, S. G., Cimino, L., and Calogero, A. E. (2017). Myo-inositol as a male fertility molecule: Speed them up. Eur. Rev. Med. Phammacol. Sci. 21, 30-35.

Coupland, N. J., Ogilivie, C. J., Hegadoren, K. M., Seres, P., Hanstock, C. C., and Allen, P. S. (2005). Decreased prefrontal myo-inositol in major depressive disorder. Biol. Psychiatry 57, 1526-1534. doi: 10.1016/j.biopsych.2005.02.027

Dai, G., Yu, H., Kruse, M., Traynor-Kaplan, A., and Hillea, B. (2016). Osmoregulatory inositol transporter SMIT1 modulates electrical activity by adjusting PI(4,5)P2 levels. Proc. Natl. Acad. Sci. U. S. A. 113, E3290-E3299. doi: 10.1073/pnas.1606348113

Di Paolo, G., and DeCamilli, P. (2006). Phosphoinositides in cell regulation and membrane dynamics. Nature 443, 651-657. doi: 10.1038/nature05185

Diamanti-Kandarakis, E., Kouli, C. R., Bergiele, A. T., Filandra, F. A., Tsianateli, T. C., Spina, G. G., et al. (1999). A survey of the polycystic ovary syndrome in the Greek island of Lesbos: hormonal and metabolic profile. J. Clinic. Endocrin. Metabol. 84, 4006-4011. doi: 10.1210/jcem.84.11.6148

Dittmer, J. C., and Douglas, M. G. (1969). Quantitative determination of phosphoinositides. Ann. N. Y. Acad. Sci. 165, 515-525. doi: 10.1111/j.17496632.1970.tb55933.x

Dona, 'G., Sabbadin, C., Fiore, C., Bragadin, M., Giorgino, F. L., Ragazzi, E., et al. (2012). Inositol administration reduces oxidative stress in erythrocytes of patients with polycystic ovary syndrome. Eur. J. Endocrinol. 166, 703-710. doi: 10.1530/EJE-11-0840

Egorova, P. A., and Bezprozvanny, I. B. (2018). Inositol 1,4,5-trisphosphate receptors and neurodegenerative disorders. FEBS Journal 285, 3547-3565. doi: 10.1111/febs. 14366

Eisesnberg, F. Jr. (1967). D-myo-Inositol-1-phosphate as product of cyclization glucose-6-phosphate and substrate for a specific phosphatase in rat testis. J. Biol. Chem. 242, 1375-1382.

Engelman, J. A., Luo, J., and Cantley, L. C. (2006). The evolution of phosphatidylinositol 3-kinases as regulators of growth and metabolism. Nat. Rev. Genet. 7, 606-619. doi: $10.1038 / \mathrm{nrg} 1879$

Grabby, K. H. (1973). The sorbitol pathway and the complications of diabetes. N. Engl. J. Med. 288, 831-836. doi: 10.1056/NEJM197304192881609
Grases, F., Ramis, M., and Costa-Bouza, A. (2000). Effects of phytate and pyrophosphate on brushite and hydroxyapatite crystallization: comparison with the action of othetr phosphates. Urol. Res. 28, 136-140. doi: 10.1007/ s002400050152

Greene, D. A., De, P. V., Jesus, Jr., and Winegrad, A. I. (1975). Effects of insulin and dietary myoinositol on impaired peripheral motor nerve conduction velocity in acute streptozotocin diabetes. J. Clin. Invest. 55 (6), 1326-1336. doi: 10.1172/ JCI108052

Gu, M., Raina, K., Agarwal, C., and Agarwal, R. (2010). Inositol hexaphosphate downregulates both constitutive and ligand-induced mitogenic and cell survival signalling and causes capsase mediated apoptotic death of human prostrate carcinoma PC-3 cells. Mol. Carcinog. 49, 1-12. doi: 10.1002/ mc. 20560

Gulino, F. A., Leonardi, E., Marilli, I., Musmesi, G., Vitale, S. G., Leanza, V., et al. (2016). Effect of treatment with myo-inositol on semen parameters of patients undergoing an IVF cycle: in vivo study. Gynecol. Endocrinol. 32, 65-68. doi: 10.3109/09513590.2015.1080680

Haris, M., Cai, K., Singh, A., Hariharan, H., and Reddy, R. (2011). In-vivo mapping of brain myo-inositol. Neuroimage 54, 2079-2085. doi: 10.1016/j. neuroimage.2010.10.017

Hayashi, E., Maeda, T., and Tomita, T. (1974a). The effect of myo-inositol deficiency on lipid metabolism in rats. I. The alteration of lipid metabolism in myo-inositol deficient rats. Biochim. Biophys. Acta 360, 134-145. doi: 10.1016/0005-2760(74)90163-5

Hayashi, E., Maeda, T., and Tomita, T. (1974b). The effect of myo-inositol deficiency on lipid metabolism in rats. II. The effect of triacylglycerol accumulation in the liver of myo-inositol deficient rats. Biochim. Biophys. Acta 360, 146-155. doi: 10.1016/0005-2760(74)90164-7

Hegsted, D. M., Hayes, K. C., Gallagher, A., and Hanford, H. (1973). Inositol deficiency: an intestinal lipodystrophy in the gerbil. J. Nutr. 103, 302-307. doi: 10.1093/jn/103.2.302

Heimark, D., McAllister, J., and Larner, J. (2013). Decreased myo-inositol to chiroinositol $(\mathrm{m} / \mathrm{c})$ ratios and increased $\mathrm{m} / \mathrm{c}$ epimerase activity in pcos theca cells demonstrate increased insulin sensitivity compared to controls. Endocr. J. doi: 10.1507/endocrj.EJ13-0423

Huang, W., Alexander, G. E., Daly, E. M., Shetty, H. U., Krasuski, J. S., Rapoport, S. I., et al. (1999). High brain myo-inositol levels in the predementia phase of Alzheimer's disease in adults with Down's syndrome: a 1H MRS study. Am. J. Psychiatry 156, 1879-1886. doi: 10.1176/ajp.156.12.1879

Isabella, R., and Raffone, E. (2012). Does ovary need D-chiro-inositol? J. Ovarian Res. 5 (14), 1-5. doi: 10.1186/1757-2215-5-14

Jyonouchi, H., Sun, S., Ijima, K., Wang, M., and Hecht, S. S. (1999). Effects of anti7,8-dihydroxy-9,10-epoxy-7,8,9,10-tetrahydrobenzo[a]pyrene on human small airway epithelial cells and the protective effects of myo-inositol. Carcinogenesis 20, 139-145. doi: 10.1093/carcin/20.1.139

Kassie, F., Kalscheuer, S., Matise, I., Ma, L., Melkamu, T., Upadhayaya, P., et al. (2010). Inhibition of vinyl carbamate induced pulmonary adenocarcinoma by indole-3-carbinol and myo-inositol in A/J mice. Carcinogenesis 31, 239-245. doi: 10.1093/carcin/bgp174

Kim, D., Jun, K. S., Lee, S. B., Kang, N. G., Min, D. S., Kim, Y. H., et al. (1997). Phospholipase C isozymes selectively couple to specific neurotransmitter receptors. Nature 389, 290-293. doi: 10.1038/38508

Kontoangelos, K., Vaidakis, N., Zervas, I., Thomadaki, O., Smaragda, C., Stavrianeas, N. G., et al. (2010). Administration of inositol to a patient with bipolar disorder and psoriasis: a case report. Cases J. 3, 1-3. doi: 10.1186/1757-1626-3-69

Lagana, A. S., Garzon, S., Casarin, J., Franchi, M., and Ghezzi, F. (2018). Inositol in polysystic ovary syndrome: restoring fertility through a pathophysiology based approach. Trends Endocr. Metabol. 29, 768-780. doi: 10.1016/j.tem.2018.09.001

Larner, J. (2002). D-chiro-inositol - Its functional role in insulin action and its deficit in insulin resistance. Int. J. Exp. Diabetes Res. 3, 47-60. doi: $10.1080 / 15604280212528$

Larner, J., Brautigan, D. L., and Thorner, M. O. (2010). D-chiro inositol glycans in insulin signaling and insulin resistance. Mol. Med. 16, 543-551. doi: 10.2119/ molmed.2010.00107

Lenie, S., and Smitz, J. (2009). Functional AR signalling is evident in an in vitro mouse follicle culture bioassay that encompasses the most stages of folliculogenesis. Biol. Reprod. 80, 685-695. doi: 10.1095/biolreprod.107.067280 
Lo Vasco, V. R., Cardinale, G., and Polonia, P. (2012). Deletion of PI-PLC $\beta 1$ gene in schizophrenia affected patients. J. Cell Mol. Med. 16, 844-851. doi: 10.1111/j.1582-4934.2011.01363.x

Lo Vasco, V. R., Longo, L., ande Polonia P. (2013). Phosphoinositide -specific phospholipase $\mathrm{C}$ beta1 gene deletion in bipolar disorder affeted patients. J. Cell Commun. Signal. 7: 25-29. doi: 10.1007/s12079-012-0182-2

Loscher, W., and Nau, H. (1985). Pharmacological evaluation of various metabolites and analogs of valproic acid: anticonvulsant and toxic potencies in mice. Neuropharmacology 24, 427-435. doi: 10.1016/0028-3908(85)90028-0

Luo, J., Manning, B. D., and Cantley, L. C. (2003). Targeting the PI3K-Akt pathway in human cancer: rationale and promise. Cancer Cell 4, 257-262. doi: 10.1016/ S1535-6108(03)00248-4

Macri, M. A., D’Alessandro, N., Di Giulio, C., Di Iorio, P., Di Luzio, S., Giuliani, P., et al. (2006). Regional changes in the metabolite profile after long-term hypoxia-ischemia in brains of young and aged rats: a quantitative proton MRS study. Neurobiol. Aging 27, 98-104. doi: 10.1016/j. neurobiolaging.2005.01.007

Majumdar, A. L., Johnson, M. D., and Henry, S. A. (1997). 1L-myo-Inositol-1phosphate synthase. Biochim. Biophys. Acta 1348, 245-256. doi: 10.1016/ S0005-2760(97)00122-7

Majumder, A. L., and Biswas, B. B. (2006). "Biology of inositols and phosphoinositides," in subcellular biochemistry (USA: Springer). doi: 10.1007/0-387-27600-9

Mc Omish, C. E., Burrows, E. L., Howard, M., and Hannan, A. J. (2008). PI-PLC $\beta 1$ knockout mice as a model of disrupted cortical development and plasticity: behavioral endophenotypes and dysregulation of RGS4 gene expression. Hippocampus 18, 824-834. doi: 10.1002/hipo.20443

McCrea, H. J., and Camilli, P. D. (2009). Mutations in phosphoinositides metabolizing enzymes and human disease. Physiology 24, 8-16. doi: 10.1152/ physiol.00035.2008

McLaurin, J., Franklin, T., Chakrabartty, A., and Fraser, P. E. (1998). Phosphatidylinositol and inositol involvement in Alzheimer amyloid-beta fibril growth and arrest. J. Mol. Biol. 278, 183-194. doi: 10.1006/jmbi.1998.1677

Michell, R. H., and Hawthorne, J. N. (1965). The site of diphosphoinositide synthesis in rat liver. Biochem. Biophys. Res. Commun. 21, 333-338. doi: 10.1016/0006-291X(65)90198-1

Minozzi, M., Nordio, M., and Pajalich, R. (2013). The combined therapy myo-inositol plus D-Chiro-inositol, in a physiological ratio, reduces the cardiovascular risk by improving the lipid profile in PCOS patients. Eur. Rev. Med. Pharmacol. Sci. 17, 537-540. doi: 10.1155/2013/424163

Nacimento, N. R. F., Less, L. M. A., Kewrntopf, M. R., Sousa, C. M., Alves, R. S., Queiroz, M. G. R., et al. (2006). Inositols prevent and reverse endothelial dysfunction in diabetic rat and rabbit vasculature metabolically and bt scavenging superoxide. PNAS 103, 218-223. doi: 10.1073/pnas.0509779103

Nagai, Y., and Funahashi, S. (1962). Phytase (myo-inositol hexaphosphate phosphohydrolase) from wheat bran. I. Purification and substrate specificity. Agri. Biol. Chem. 26, 794-803. doi: 10.1080/00021369.1962.10858050

Nakayama, J., Yamamoto, N., Hamano, K., Iwasaki, N., Ohta, M., Nakahara, S., et al. (2004). Linkage and association of febrile seizures to the IMPA2 gene on human chromosome 18. Neurology 63, 1803-1807. doi: 10.1212/01. WNL.0000144499.34164.E0

Nestler, J. E. (1997). Role of hyperinsulinemia in the pathogenesis of the polycystic ovary syndrome, and its clinical implications. Semin. Reprod. Endocrin. 15, 111-122. doi: 10.1055/s-2007-1016294

Nishino, H., Murakoshi, M., Masuda, M., Tokuda, H., Satomi, Y., Onozuka., M., et al. (1999). Suppression of lung and liver carcinogenesis in mice by oral administration of myo-inositol. Anticancer Res. 19, 3663-3664.

Nonaka, M., Kohmura, E., Yamashita, T., Yamauchi, A., Fujinaka, T., Yoshimine, T., et al. (1999). Kainic acid-induced seizure upregulates $\mathrm{Na}(+) /$ myo-inositol cotransporter mRNA in rat brain. Brain Res. Mol. Brain Res. 70, 179-186. doi: 10.1016/S0169-328X(99)00127-8

Odom, A. R., Stahlberg, A., Wente, S. R., and York, J. D. (2000). A role for nuclear inositol 1,4,5-trisphosphate kinase in transcriptional control. Science 287, 2026-2029. doi: 10.1126/science.287.5460.2026

Osaki, M., Oshimura, M., and Ito, H. (2004). PI3K-Akt pathway: its functions and alterations in human cancer. Apoptosis 9, 667-676. doi: 10.1023/B:APPT.0000045801.15585.dd
Palmano, K. P., Whiting, P. H., and Hawthorne, J. N. (1977). Free and lipid myoinositol in tissues from rats with acute and less severe streptozotocin-induced diabetes. Biochem. J. 167, 229-235. doi: 10.1042/bj1670229

Parenti, A., Filippi, S., Amerini, S., Granger, H. J., Fazzini, A., and Ledd, F. (2000). Inositol phosphate metabolism and nitric oxide synthase activity in endothelial cells are involved in the vaso-relaxant activity of Nebivolol. J. Pharmacol. Exp. Ther. 299, 698-703.

Parthasarathy, R., and Eisenberg, F. Jr. (1986). The inositol phospholipids: a stereochemical view of biological activity. Biochem. J. 235, 313-322. doi: $10.1042 / \mathrm{bj} 2350313$

Paulus, H., and Kennedy, E. P. (1960). The enzymatic synthesis of inositol monophosphatide. J. Biol. Chem. 235, 1303-1311.

Plouvier, V. (1963). "Distribution of aliphatic polyols and cyclitol," in Chemical plant taxonomy. Ed. Swain, T. (New York: Academic Press), 313-336. doi: 10.1016/ B978-0-12-395540-1.50015-4

Regan, T. J., Khan, M. I., Jesrani, M. U., Oldewurtel, H. A., and Ettinger, P. O. (1973). "Alteration of myocardial function and metabolism in chronic diabetes mellitus," in Recent advances in studies of cardiac structure and metabolism. Ed. Dhalla, N. S. (Baltimore: University Park).

Ren, Q. (2019). Soluble epoxide hydrolase inhibitor: a novel potential therapeutic or prophylactic drug for psychiatric disorders. Front. Pharmacol. 10, 420. doi: 10.3389/fphar.2019.00420

Reyes-Munoz, E., Sathyapalan, T., Rossetti, P., Shah, M., Long, M., Buscema, M., et al. (2018). Polycystic ovary syndrome: implication for drug metabolism on assisted reproductive techniques-a literature review. Adv. Ther. 35, 1805-1815. doi: 10.1007/s12325-018-0810-1

Sabuncu, T., Vural, H., Harma, M., and Harma, M. (2001). Oxidative stress in polycystic ovary syndrome and its contribution to the risk of cardiovascular disease. Clin. Biochem. 34, 407-413. doi: 10.1016/s0009-9120(01)00245-4

Saiardi, A., Bhandari, R., Resnick, A. C., Snowman, A. M., and Snyder, S. H. (2004). Phosphorylation of proteins by inositol pyrophosphates. Science 306, 2101-2105. doi: 10.1126/science.1103344

Saltiel, G., Shamir, A., Shapiro, J., Ding, D., Dalton, E., Bialer, M., et al. (2004). Valproate decreases inositol biosynthesis. Biol. Psychiatry 56, 868-874. doi: 10.1016/j.biopsych.2004.08.027

Saltiel, G., Shiley, M., Kofman, O. and Belmaker, R. H. (2007). Effect of valproate derivatives on human brain myo-inositol-1-phosphate synthase activity and amphetamine induced rearing. Pharm. Rep. 59, 402-407.

Seelan, R. S., Lakshmanan, J., Manuel, F., Casanova, M. F., and Parthasarathy, R. N. (2009). Identification of myo-inositol-3-phosphate synthase isoforms: characterization, expression, and putative role of a 16-Kda $\gamma_{c}$ isoform. J. Biol. Chem. 284, 9443-9457. doi: 10.1074/jbc.M900206200

Shaktin, A. J., and Tatum, E. L. (1961). The relationship of M-inositol to morphology of Neurospora crassa. Am. J. Bot. 48, 760-771. doi: 10.1002/j.15372197.1961.tb11708.x

Shen, X., Xiao, H., Ranallo, R., Wu, W. H., and Wu, C. (2003). Modulation of ATP-dependent chromatin-remodeling complexes by inositol polyphosphates. Science 299, 112-114. doi: 10.1126/science. 1078068

Sherman, W. R., Stewart, M. A., Kurien, M. M., and Goodwin, S. L. (1968). The measurement of myo-inositol, myo-inosose-2 and scyllo-inositol in mammalian tissues. Biochim. Biophys. Acta 158, 197-205. doi: 10.1016/0304-4165(68)90131-1

Shimon, H., Agam, G., Belmaker, R. H., Hyde, T. M., and Kleinman, J. E. (1997). Reduced frontal cortex inositol levels in postmortem brain of suicide victims and patients with bipolar disorder. Am. J. Psychiatry 154, 1148-1150. doi: 10.1176/ajp.154.8.1148

Shirayama, Y., Takahashi, M., Osone, F., Hara, A., and Okubo, T. (2017). Myoinositol, glutamate, and glutamine in the prefrontal cortex, hippocampus, and amygdala in major depression. Biol. Psychiatry: Cogn. Neurosci. Neuroimag. 2, 196-204. doi: 10.1016/j.bpsc.2016.11.006

Siger, M., Schuff, N., Zhu, X., Miller, B. L., and Weiner, M. W. (2009). Regional myo-inositol concentration in mild cognitive impairment using ${ }^{1} \mathrm{H}$ magnetic resonance spectroscopic imaging. Alzheimer Dis. Assoc. Disord. 23, 57-62. doi: 10.1097/WAD.0b013e3181875434

Simi, G., Genazzani, A. R., Obino, M. E. R., Papini, F., Pinelli, S., Cela, V., et al. (2017). Inositol and in vitro fertilization with embryo transfer. Intl. J. Endocrinol. 5469409, 1-5. doi: 10.1155/2017/5469409 
Suh, P. G., Park, J., Manjoli, L., Cocco, L., Peak, J. C., Katan, M., et al. (2008). Multiple roles of phosphoinositides specific phospholipase C isozymes. $B M B$ Reports 41, 415-434. doi: 10.5483/BMBRep.2008.41.6.415

Tsverava, L., Kandashvili, M., Margvelani, G., Lortkipanidze, T., Gamkrelidze, G., Lepsveridze, E., et al. (2019). Long-term effects of myo-inositol on behavioural seizures and biochemical changes evoked by kainic acid induced epileptogenesis. Biomed. Res. Int. doi: 10.1155/2019/4518160

Urrila, A. S., Hakkarainen, A., Castaneda, A., Paunio, T., Marttunen, M., and Lundbom, N. (2017). Frontal cortex Myo-inositol is associated with sleep and depression in adolescents: a proton magnetic resonance spectroscopy study. Neuropsychobiology 75, 21-31. doi: 10.1159/000478861

Vendrov, A. E., Vendrov, K. C., Smith, A., Yuan, J., et al. (2015). NOX4 NADPH oxidase-dependent mitochondrial oxidative stress in aging-associated cardiovascular disease. Antioxid. Redox Signal. 23, 1389-1409. doi: 10.1089/ ars.2014.6221

Voronov, S. V., Frere, S. G., Giovedi, S. et al. (2008). Synaptojanin 1 linked phosphoinositide dyshomeostais and cognitive deficits in mouse models of Down's Syndrome. Proc. Natl. Acad. Sci. USA. 105, 9415-9420. doi: 10.1073/ pnas. 0803756105

Vucenic, I., and Shamsuddin, A. M. (2003). Cancer inhibition by inositol hexaphosphate $\left(\mathrm{IP}_{6}\right)$ and inositol: from laboratory to c linic. J. Nutr. 133, 3778S-3784S. doi: 10.1093/jn/133.11.3778S

Vucenic, I., and Shamsuddin, A. M. (2006). Protection against cancer by dietary $\mathrm{IP}_{6}$ and inositol. Nutr. Cancer 55, 109-125. doi: 10.1207/s15327914nc5502_1

Wattenberg, L. W. (1996). Chemoprevention of cancer. Prev. Med. 25, 44-45. doi: 10.1006/pmed.1996.0015
Wattenberg, L. W. (1999). Chemoprevention of pulmonary carcinogenesis by myoinositol. Anticancer Res. 19, 3659-3661.

Wellard, R. M., Briellmann, R. S., Prichard, J. W., Syngeniotis, A., and Jackson, G. D. (2003). Myoinositol abnormalities in temporal lobe epilepsy. Epilepsia 44, 815821. doi: 10.1046/j.1528-1157.2003.44102.x

York, J. D., Odom, A. R., Murphy, R., Ives, E. B., and Wente, S. R. (1999). A phospholipase C-dependent inositol polyphosphate kinase pathway required for efficient messenger RNA export. Science 285 96-100. doi: 10.1126/ science.285.5424.96

Yuan, T. L., and Cantley, L. C. (2008). PI3K pathway alterations in cancer: variations on a theme. Oncogene 27, 5497-5510. doi: 10.1038/onc.2008.245

Zhu, X., Schu, N., Kornak, J., et al. (2006). Effects of Alzheimer disease on fronto-parietal brain $\mathrm{N}$-acetyl aspartate and myo-inositol using magnetic resonance spectroscopic imaging. Alzheimer Dis. Assoc. Disord. 20, 77-85. doi: 10.1097/01.wad.0000213809.12553.fc

Conflict of Interest: The author declares that the research was conducted in the absence of any commercial or financial relationships that could be construed as a potential conflict of interest.

Copyright $\odot 2019$ Chhetri. This is an open-access article distributed under the terms of the Creative Commons Attribution License (CC BY). The use, distribution or reproduction in other forums is permitted, provided the original author(s) and the copyright owner(s) are credited and that the original publication in this journal is cited, in accordance with accepted academic practice. No use, distribution or reproduction is permitted which does not comply with these terms. 